\title{
Rates of inbreeding and genetic diversity in Canadian Holstein and Jersey cattle
}

\author{
K. Stachowicz, ${ }^{\star}$ M. Sargolzaei, ${ }^{*} \dagger$ F. Miglior, $¥ \S^{1}$ and F. S. Schenkel ${ }^{\star}$ \\ ${ }^{*}$ Centre for Genetic Improvement of Livestock, Department of Animal and Poultry Science, University of Guelph, Guelph, Ontario, \\ Canada, N1G 2W1 \\ †L'Alliance Boviteq, Saint-Hyacinthe, Quebec, Canada, J2T 5H1 \\ ‡Guelph Food Research Centre, Agriculture and Agri-Food Canada, Guelph, Ontario, Canada, N1G 5C9 \\ §Canadian Dairy Network, Guelph, Ontario, Canada, N1K 1E5
}

\section{ABSTRACT}

The accumulation of inbreeding and the loss of genetic diversity is a potential problem in the modern dairy cattle breeds. Therefore, the purpose of this study was to analyze the pedigrees of Canadian Holstein and Jersey cattle to estimate the past and current rates of inbreeding and genetic diversity, and to identify the main causes of diversity loss. Completeness and depth of the pedigrees were good for both breeds. For Holsteins, the average rates of inbreeding per generation showed a decreasing trend in recent years when compared with the 1990s. The estimated current effective population size was about 115 for Holsteins and is not expected to significantly change in the near future if generation intervals stay at current value, as rates of increase in inbreeding and coancestry showed decreasing trends. For Jerseys, the estimated effective population size was about 55 and it is expected to decrease in the near future due to the observed increasing rates of coancestry and inbreeding. Ancestors with the highest marginal genetic contributions to the gene pool in current years and with the highest contributions to inbreeding were identified. The 2 most heavily used and represented ancestors in the Holstein pedigree (i.e., Round Oak Rag Apple Elevation and his son Hanoverhill Starbuck), accounted for $30 \%$ of inbreeding. Analyses revealed that the most important cause of genetic diversity loss in both breeds was genetic drift accumulated over nonfounder generations, which occurred due to small effective population size. Therefore, a need exists in both breeds, particularly in Jerseys, for managing selection and mating decisions to control future coancestry and inbreeding, which would lead to better handling of the effective population size.

Key words: inbreeding, genetic diversity, pedigree analysis

Received March 31, 2010

Accepted June 14, 2011

${ }^{1}$ Corresponding author: miglior@cdn.ca

\section{INTRODUCTION}

The level of inbreeding in dairy cattle has been given attention since the first half of last century. Conventional breeding programs may lead to high rates of genetic progress but also cause genetic erosion in selected populations. A large overall population size does not mean that the population is free from problems typical for small, endangered populations. For instance, the world Holstein population suffers from inbreeding depression (e.g., González-Recio et al., 2007; Miglior et al., 2008) and significant loss of genetic diversity (e.g., Hagger, 2005; Sørensen et al., 2005).

Miglior and Burnside (1995) estimated inbreeding rates using more than 3 million Canadian Holsteins born up to 1990 and reported rates of $0.07,-0.03$, and $0.21 \%$ per year for bulls born before 1979, between 1979 and 1986, and between 1987 and 1990, respectively. For cows, corresponding figures were $0.06,0$, and $0.07 \%$. The rate of inbreeding was higher in birth years from 1990 to 1999 , varying from 0.14 to $0.29 \%$ per year (Miglior, 2000). Kearney et al. (2004) reported annual rates of inbreeding in Holsteins in the United Kingdom of $0,0.03$, and $0.17 \%$ for the periods before 1968, 1968 to 1991, and 1992 to 2002, respectively. Sørensen et al. (2005) also reported increasing annual rates of inbreeding in Danish Holstein and Jersey cattle, with rates of 0.15 and $0.22 \%$ for the periods 1983 to 1992 and 1993 to 2003 in Holsteins and 0.10 and $0.20 \%$ for the periods 1977 to 1991 and 1993 to 2003 in Jerseys. All of these reports show an increase in inbreeding rates in the 1990s, which coincides with the implementation of genetic evaluations based on BLUP and more intensive use of AI.

In 2004, Canadian Dairy Network (Guelph, ON) introduced the $\mathrm{R}$-values into the routine genetic evaluations (Van Doormaal et al., 2003). An R-value represents the average genetic relationship of an animal to the active cow population within each dairy breed. In a study by Van Doormaal et al. (2005), the R-values were used to assess the amount of common genes between 
Canadian Holstein cows born in 2004 and Canadian and foreign proven bulls born in 1999. Bulls from Canada and Spain were the most related to Canadian cows with $\mathrm{R}$-values of 11.7 and $11.4 \%$, respectively. The analysis of pedigree revealed that $93 \%$ of animals born between 2003 and 2005 were descendants of Hanoverhill Starbuck (Canadian bull) and 99\% of his father, Round Oak Rag Apple Elevation (US bull; Van Doormaal et al., 2005). The Canadian Dairy Network regularly publishes individual inbreeding coefficients, average inbreeding levels, and average rates of inbreeding for all Canadian dairy cattle breeds (Canadian Dairy Network, 2008). The average rate of inbreeding for the period between 2000 and 2007 was reported to be 0.08 and $0.10 \%$ per year for Holsteins and Jersey, respectively.

The objective of this study was to perform an indepth analysis of the most recently updated pedigree of Canadian Holstein and Jersey cattle to assess the past and current rates of inbreeding and genetic diversity, and to determine the main causes of diversity loss.

\section{MATERIALS AND METHODS}

\section{Pedigree Data}

The pedigree records of 8,764,141 Canadian Holsteins born between 1883 and 2008, and 394,505 Canadian Jersey cattle born between 1917 and 2007 were provided by the Canadian Dairy Network (Guelph, ON, Canada). It should be noted that the Jersey pedigree includes animals born until 2007 instead of 2008, because data from this breed was received and analyzed before data from Holstein breed, when the 2008 records were not all available. Three groups of animals were considered: a) All animals in the pedigree (referred to further as all animals), b) proven bulls, and c) cows with at least 1 complete lactation with records (referred to further as cows). In total, 5,117,503 Holstein cows born between 1939 and 2007 and 169,439 Jersey cows born between 1942 and 2006 met this criterion. In this study, a proven bull was defined as a sire born between 1975 and 2002 with at least 10 daughters in 10 herds with protein yield record, or born between 2003 and 2006 with at least 10 progeny in 10 herds with direct calving ease record. The year 1975 was used as the first year where a continuous progeny testing scheme of a significant size began in Canada, with 10,328 and 718 proven Holstein and Jersey bulls, respectively. The numbers of animals in each of the groups by year of birth are shown in Figure 1.

\section{Pedigree Completeness Measures}

Completeness and depth of the pedigree are important factors, which affect the estimated inbreeding coef- ficients and relationship among animals and, to a lesser extent, affect also the estimated generation intervals and effective numbers of founders and ancestors. Three different measures were used to assess the completeness of the pedigree: percentage of animals with both parents known, discrete generation equivalents, and pedigree completeness index. The average number of discrete generation equivalents was calculated for each individual as

$$
g e_{j}=\sum_{i=1}^{n_{j}} \frac{1}{2^{g_{i j}}}
$$

where $g e_{j}$ is generation equivalent of animal $j, n_{j}$ is the number of known ancestors of animal $j$, and $g_{i j}$ is the number of generations between ancestor $i$ and animal $j$ (Sölkner et al., 1998). The average number of discrete generations provides an indication of how many complete discrete generations were present in a given pedigree.

Pedigree completeness index (PCI), as proposed by MacCluer et al. (1983), was calculated for all individuals for $5,10,15$, and 20 generations back in the pedigree:

$$
P C I=\frac{2 C_{\text {sire }} C_{\text {dam }}}{C_{\text {sire }}+C_{\text {dam }}},
$$

where $C_{\text {sire }}$ and $C_{d a m}$ are the indexes for paternal and maternal contribution, respectively, and

$$
C=\frac{1}{d} \sum_{i=1}^{d} a_{i}
$$

where $a_{i}$ is the proportion of ancestors known in generation $i$ and $d$ is a preset number of generations traced back in pedigree. Pedigree completeness index, as a harmonic mean of parental contributions, is always zero when either parent is unknown regardless how deep and complete the pedigree of the other parent is. Inbreeding can also only be estimated if information on both parents' ancestors is available; therefore, PCI is an important measure of pedigree quality for inbreeding estimation.

\section{Measures of Genetic Diversity}

Inbreeding Coefficient. The inbreeding coefficient of each individual in the pedigree was calculated using an algorithm described by Sargolzaei at al. (2005), which is based on the indirect method proposed by Colleau (2002). When pedigree is incomplete, inbreeding is usually underestimated. Therefore, inbreeding was 
a)

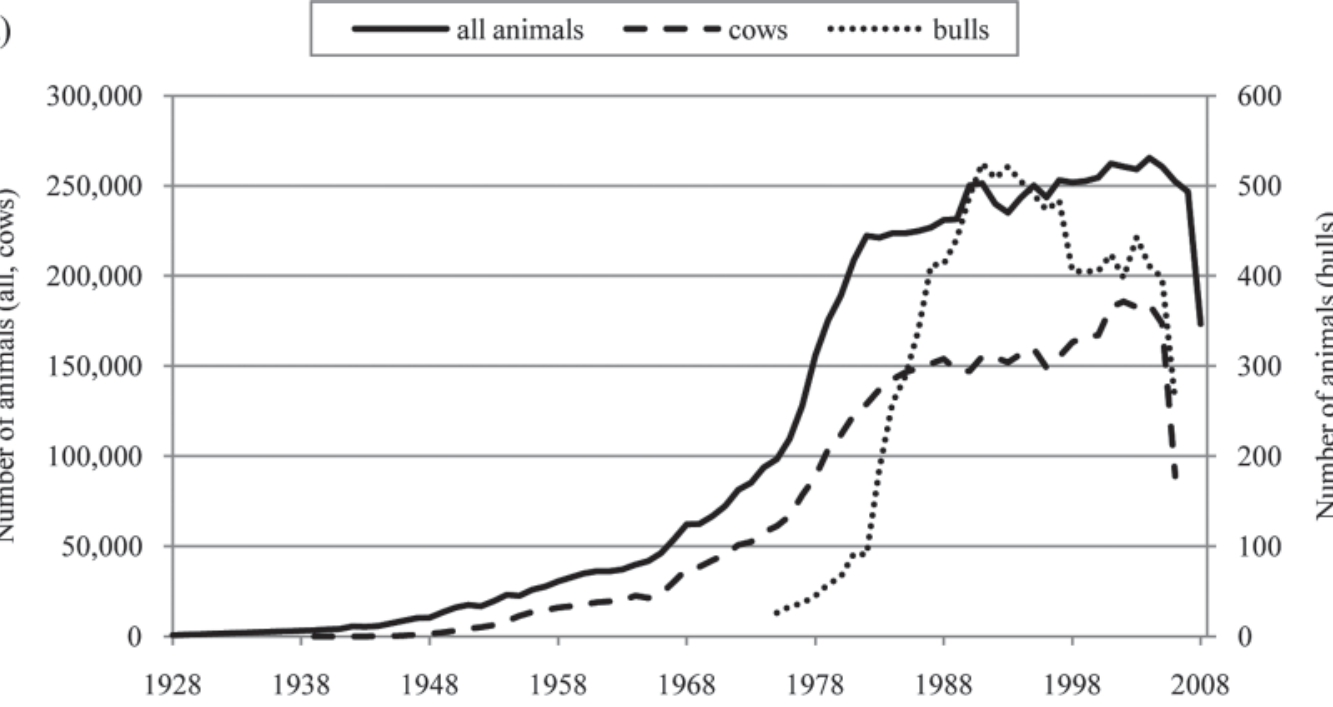

Year of birth - Holstein

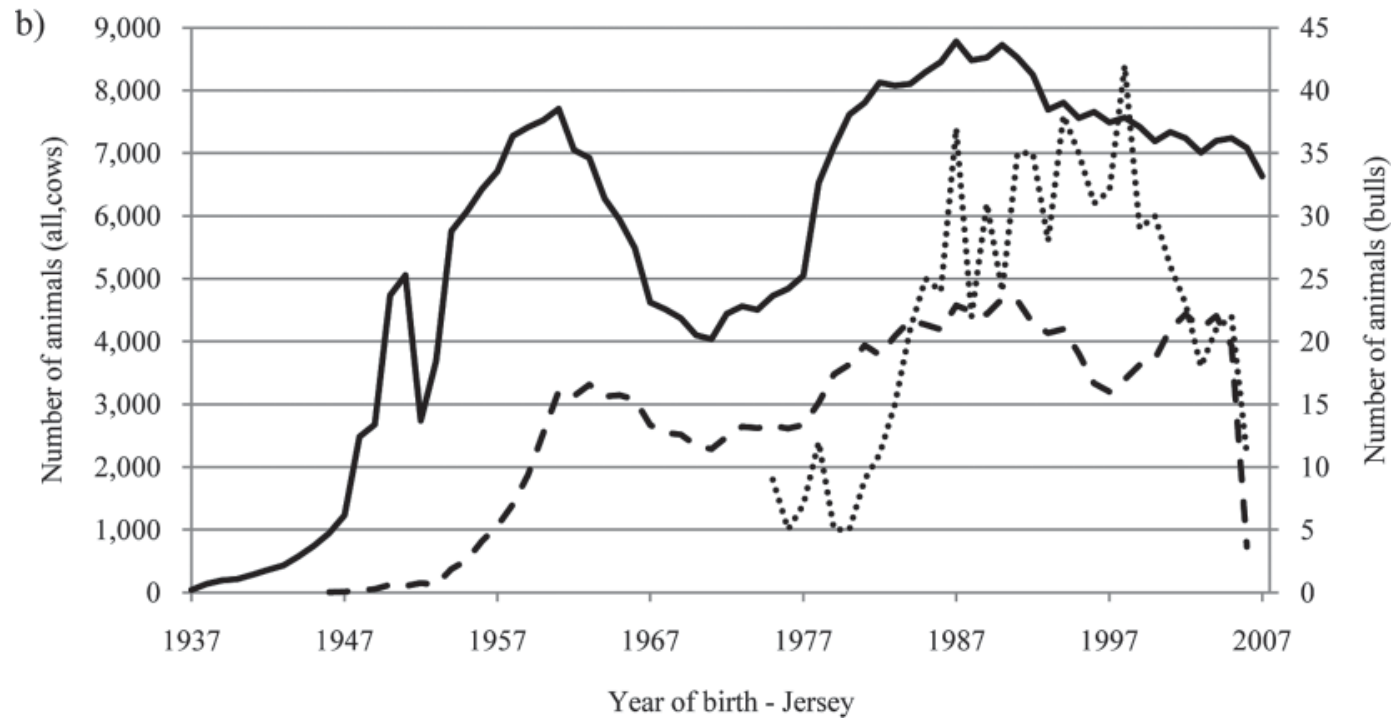

Figure 1. The number of animals born per year for selected birth years (Holstein, 1a; Jersey, 1b).

also calculated by the method proposed by VanRaden (1992), which assumes that unknown parents are related to other parents by twice the mean inbreeding coefficient of progeny of known parents.

Coefficient of Coancestry. The coefficient of coancestry, which is half of the relationship coefficient, was used for predicting future rates of inbreeding (Falconer and Mackay, 1996) and also to assess the degree of relationship within breed, and, jointly with the inbreeding coefficient, to assess the degree of nonrandom mating.
Effective Population Size. The effective population size $\left(N_{e}\right)$ was calculated as

$$
N_{e}=\frac{1}{2 \Delta F_{y} L},
$$

where $\Delta F_{y}$ is the annual rate of inbreeding and $L$ is the average generation interval for the corresponding birth cohort (Wright, 1931). Therefore, $\Delta F_{y} L$ is the rate of inbreeding per generation. Rates of inbreeding were calculated as the difference in inbreeding levels between 2 
consecutive years. Generation interval was defined as the average age of parents when their progeny was born and was calculated separately for 4 selection pathways (sire of sons, sires of daughters, dams of sons, and dams of daughters); the average generation interval was the mean value of those pathways. The predicted future effective population size was calculated based on rates of coancestry for different time periods, assuming random mating within breed.

Effective Number of Founders. The effective number of founders [or founder equivalent $\left(f_{e}\right)$ ] is a measure of founder contributions to the population and is defined as the number of equally contributing founders, which would give the same amount of genetic diversity that is present in the current population. The $f_{e}$ was calculated as in Lacy (1989) and it is usually much smaller than the actual number of founders in pedigree (animals with both parents unknown). This reflects the unequal contributions of founders to the current population due to selection rates (probability of becoming a parent and variation of family size). According to the theory of long-term genetic contributions, the contributions of founders are expected to converge after several generations (Bijma and Woolliams, 1999) and remain constant afterward.

Effective Number of Founder Genomes. In a real population of limited size, the loss of genetic diversity would occur due to genetic drift, even if founders would contribute equally to this population (Lacy, 1989). Therefore, the effective number of founder genomes [or founder genome equivalent $\left(\boldsymbol{f}_{\boldsymbol{g e}}\right)$ ] is defined as the number of equally contributing founders with no loss of founder alleles that would give the same amount of genetic diversity as is present in the reference population. The $f_{g e}$ was calculated as in Caballero and Toro (2000). The $f_{g e}$ accounts for the loss of genetic diversity that occurred in the population due to genetic drift and bottlenecks.

Effective Number of Nonfounders. The effective number of nonfounders $\left(N_{\text {enf }}\right)$ was calculated as

$$
N_{\text {enf }}=\left(\frac{1}{f_{g e}}-\frac{1}{f_{e}}\right)^{-1}
$$

where $N_{\text {enf }}$ accounts for the contributions of nonfounders and, therefore, for loss of genetic diversity due to drift accumulated over nonfounder generations (Caballero and Toro, 2000).

Effective Number of Ancestors. The effective number of ancestors $\left(N_{a}\right)$ was calculated as in Boichard et al. (1997), considering the 1,000 most-contributing ancestors. The $N_{a}$, when compared with the effective number of founders, provides evidence of bottlenecks that occurred in population in the past.

Measures of the loss of genetic diversity can be derived from $f_{e}, f_{g e}$, and $N_{e n f}$. The amount of genetic diversity $(\boldsymbol{G D})$ in the reference population was calculated according to Lacy (1995) as

$$
G D=1-\frac{1}{2 f_{g e}} .
$$

When expressed as $1-G D$, it measures the genetic diversity lost in the population since the founder generation, as a consequence of both bottlenecks and genetic drift. Calculated as $1-G D^{*}$, where

$$
G D^{*}=1-\frac{1}{2 f_{e}}
$$

it estimates the loss of genetic diversity that occurred in the population due to the unequal contributions of founders before their contributions converged (Caballero and Toro, 2000). The difference between $G D^{*}$ and $G D$ is

$$
G D^{*}-G D=\frac{1}{2 N_{e n f}}
$$

and it measures the loss of diversity by genetic drift accumulated over nonfounder generations (Caballero and Toro, 2000; Honda et al., 2004).

For Holsteins, the reference population included animals born between 2000 and 2008 and for Jerseys it included animals born between 2000 and 2007.

\section{Degree of Nonrandom Mating}

The degree of nonrandom mating within both breeds was measured by the correlation of genes within individuals relative to the correlation of genes taken at random from the population $(\alpha)$ as in Caballero and Toro (2000). This coefficient gives an indication of the deviation from Hardy-Weinberg equilibrium expectations and it is related to inbreeding coefficient and coancestry by $(1-F)=(1-f) \times(1-\alpha)$, where $F$ and $f$ are the inbreeding and coancestry coefficients, respectively (Wright, 1969).

\section{Decomposition of Inbreeding into Ancestral Components}

The inbreeding coefficient of Holsteins born between 2000 and 2008 and Jerseys born between 2000 and 2007 
was decomposed into ancestral components (Colleau and Sargolzaei, 2008). Vector $\mathbf{u}(r \times 1)$, containing contributions to inbreeding of nodal common ancestors, who form inbreeding loops, was obtained by Gaussian elimination of $\mathbf{m}=\mathbf{C u}$, where $\mathbf{C}(r \times r)$ is an upper triangular matrix with elements

$$
c_{k i}=0.25\left(t_{s_{i} k}^{2}+t_{d_{i} k}^{2}\right) d_{k k},
$$

where $t_{s_{i} k}$ and $t_{d_{i} k}$ are elements of matrix $\mathbf{T}(r \times r)$, containing the fractions of the genes that ancestor $k$ passed to the sire $(s)$ and dam $(d)$ of descendant $i ; d_{k k}$ is an element of diagonal matrix $\mathbf{D}(r \times r)$ containing Mendelian sampling variances; and $c_{k k}=d_{k k}$. Vector $\mathbf{m}$ $(r \times 1)$ contains contributions of Mendelian sampling variances of ancestor $k$ with elements $m_{k}=0.5 t_{s_{i} k} t_{d_{k} k} d_{k k}$, where $r$ is the number of animals in the reference population.

Decomposition of inbreeding allows assessing when and by which ancestors the inbreeding in the reference population was created.

\section{Software Used}

Inbreeding, effective number of founders, effective number of founder genomes, and effective number of nonfounders, decomposition of inbreeding into ancestral components, as well as pedigree statistics and pedigree completeness index were calculated using the CFC software (Sargolzaei et al., 2006). The EVA software (Berg et al., 2007) was used to calculate coefficients of coancestry and average number of discrete generation equivalents. The Pedig package by Boichard (2002) was used to calculate generation intervals, effective number of ancestors, and to identify ancestors with the highest genetic contributions.

\section{RESULTS}

\section{Pedigree Completeness}

In the Canadian Holstein pedigree, the percentage of animals with both parents known was above $90 \%$ since the beginning of the 1980s for all animals and since the 1970s for cows. All proven bulls had both parents known. The longest ancestral path traced back in the pedigree was 48 , whereas the average of all ancestral paths was 29. The average number of discrete generation equivalents reached 15.5 in 2006 for all animals and cows, and 16.5 for bulls. Figure 2a depicts the average PCI by year of birth, considering 5,15 , and 25 generations for all animals, and 5 and 15 generations for cows and proven bulls. The PCI of cows was slightly higher than of all animals with average PCI value over $90 \%$ in recent years, considering 5 generations back. The PCI of proven bulls was $100 \%$ for the last 4 decades, considering 5 generations back, and close to $90 \%$ in recent years, considering 15 generations back in the pedigree.

In the Canadian Jerseys pedigree, the percentage of animals born after 1956 with both parents known was about $95 \%$ for all animals, above $97 \%$ for cows and $100 \%$ for proven bulls (data not shown). The longest ancestral path traced back in the pedigree was 23 , in contrast to an average of 9.5 for an average animal (data not shown). The average number of discrete generation equivalents in 2006 was 9.8, 10.1, and 9.8 for all animals, cows, and proven bulls, respectively (data not shown). Figure $2 \mathrm{~b}$ depicts the average PCI for each birth cohort, considering 5, 10, 15, and 20 generations back in the pedigree for all animals, and 5 and 10 generations back for both bulls and cows. Contrarily to Holsteins, the PCI of cows was the highest, followed by the PCI of bulls and all animals in pedigree. When traced 5 generations back over the last 2 decades, the PCI values were above $90 \%$ for bulls, and above $95 \%$ for cows.

\section{Annual Rates of Inbreeding and Coancestry}

Table 1 presents the average estimated rates of inbreeding per year of birth $(\Delta \mathrm{F})$ for 10-year periods since 1950 for the 2 breeds. The rates for Holsteins fluctuated over time, being highest in the 1990s, when they started to decline until recent years. For Jerseys, the inbreeding rates fluctuated less over time, being lowest in the 1980s, when they started to increase until recent years.

The trends in inbreeding levels for the 2 breeds are depicted in Figure 3, using both regular inbreeding coefficients and coefficients accounting for missing pedigree information according to the method of VanRaden (1992). For Holsteins, the amount of inbreeding recovered by accounting for missing pedigree records was relatively large (2-fold); however, the estimated annual rate of inbreeding since 1970 was similar in both cases [i.e., not accounting or accounting for missing pedigree records $(0.013 \%$ vs. $0.014 \%$ per year, respectively; data not shown)].

For Jerseys, the amount of inbreeding recovered by accounting for missing pedigree records was small and the estimated rate of inbreeding since 1970 was also similar when not accounting or accounting for missing pedigree records $[0.012 \%$ vs. $0.011 \%$ per year, respectively (data not shown)].

Figure 4 presents the average inbreeding coefficient of all animals born in a given year, the average coancestry coefficient between their sires and dams, and 


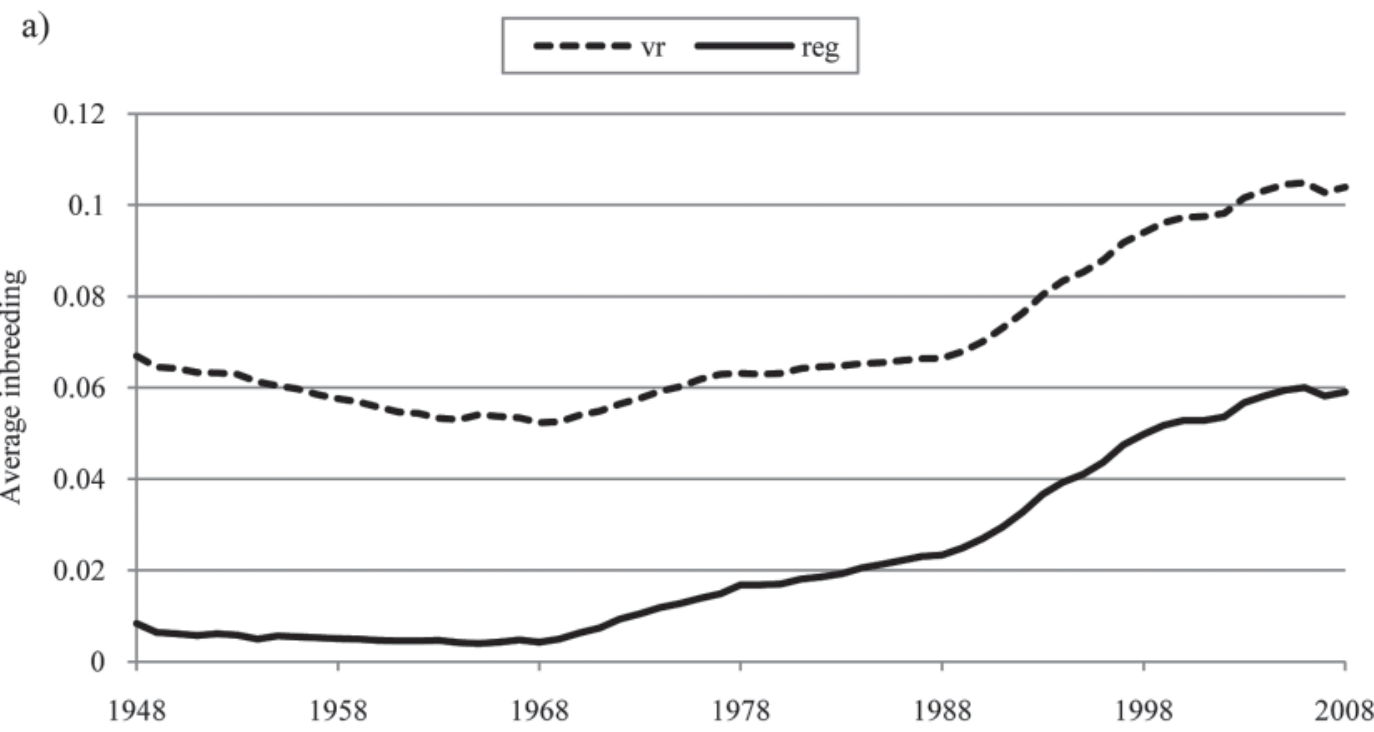

Year of birth - Holstein

b)

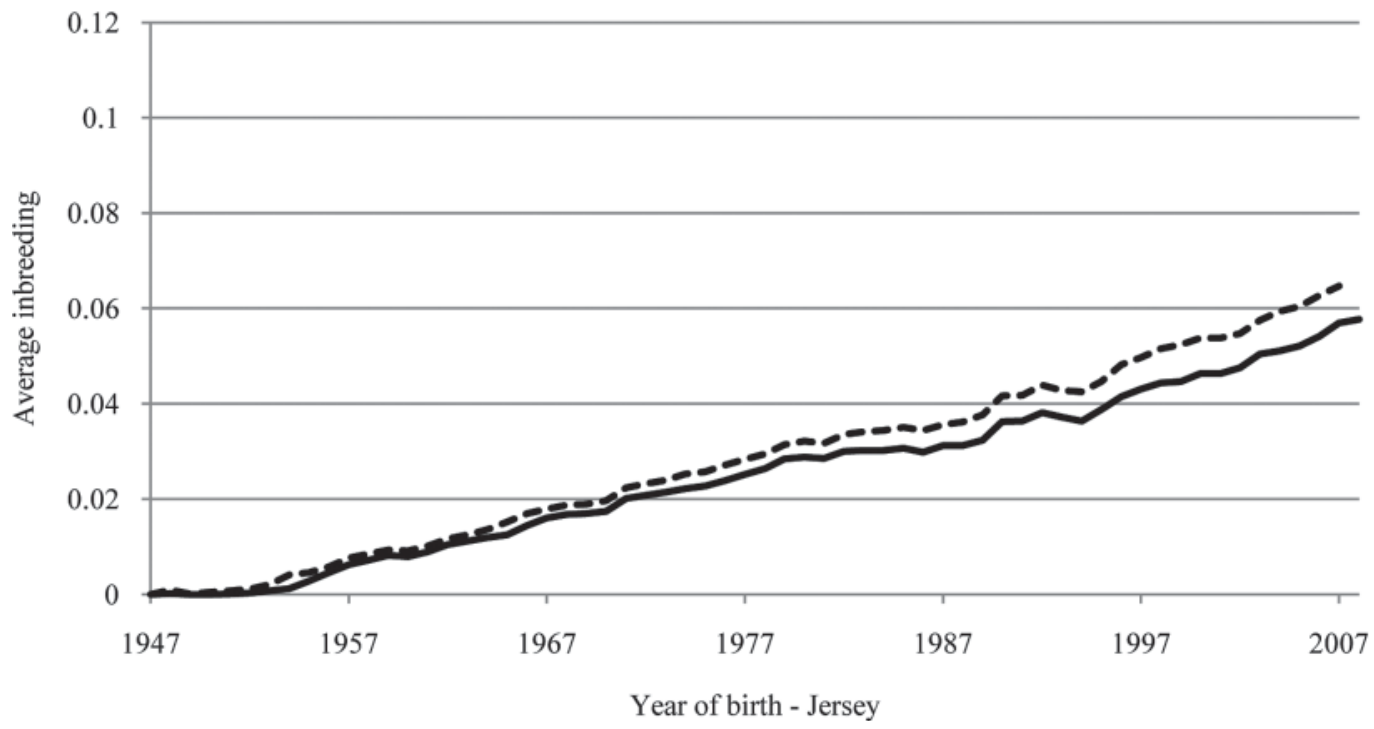

Figure 3. Average inbreeding coefficients: regular inbreeding (reg) and inbreeding estimated accounting for missing pedigree records using the VanRaden (1992) method (vr) for all animals (Holstein, 3a; Jersey, 3b).

positive since the 1950s, whereas for Holsteins, it was positive up to 1980 , but mostly negative afterward.

\section{Generation Interval and Effective Population Size}

Figure 5 shows generation intervals for 4 selection pathways, as well as their average value for both breeds. The average generation interval in Holsteins decreased over time from values close to 7 in the 1970s (when the progeny test schemes started in Canada) to slightly above 5 in recent years. The dam of daughter pathway showed a stable trend over the years, with an average generation interval of 4.2 in recent years. In Jerseys, the average generation interval decreased from $7 \mathrm{yr}$ in the beginning of the 1970s to $5.8 \mathrm{yr}$ in recent years. For dams of daughters, it was $5.2 \mathrm{yr}$ at the beginning of the 1970s and 4.4 in recent years. For both breeds, generation intervals for sires of sons were 9 to $10 \mathrm{yr}$ in the 1970s and 1980s, but decreased to about $7 \mathrm{yr}$ in 2006 .

The average estimated generation interval, average rates of inbreeding $(\Delta \mathrm{F})$, and coancestry $(\Delta \mathrm{C})$ per generation, $N_{e}$, and predicted future $N_{e}$, based on rates of 
a)
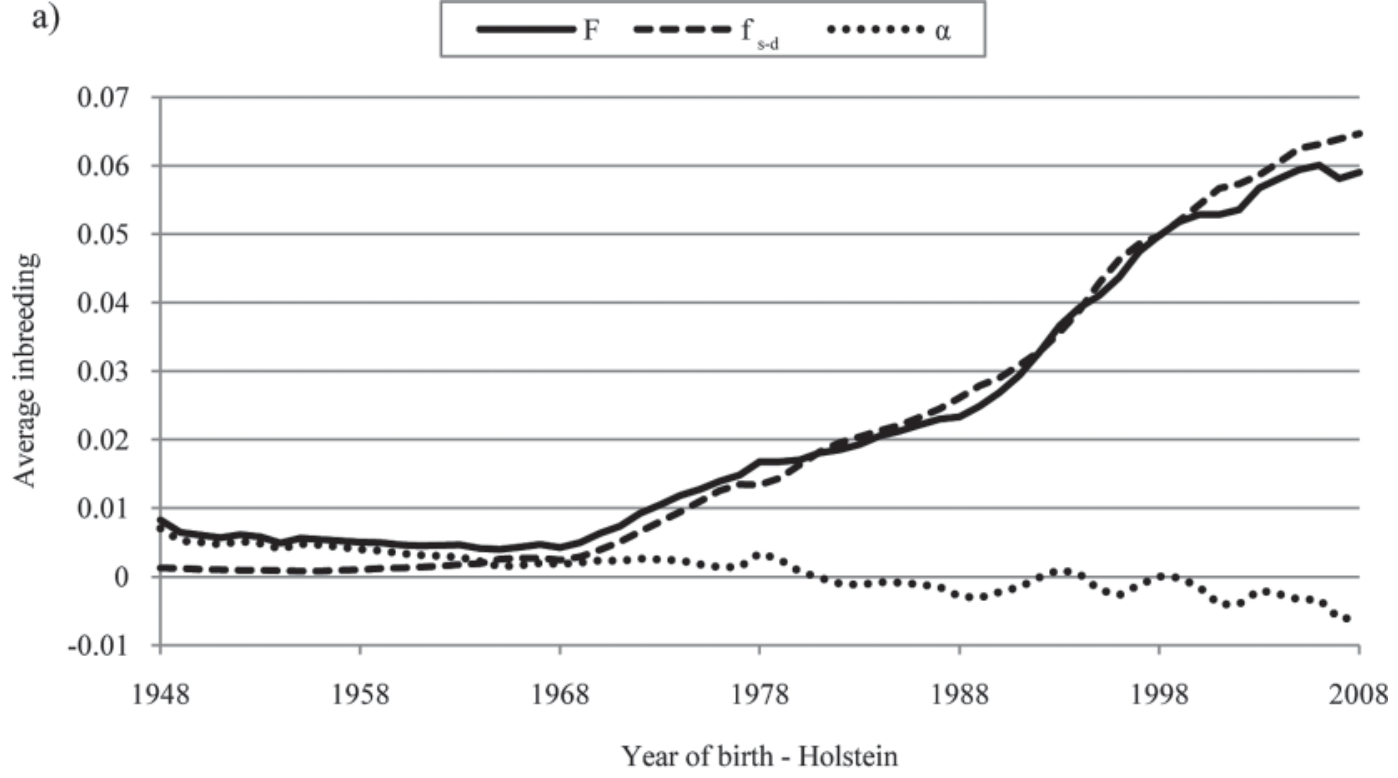

b)

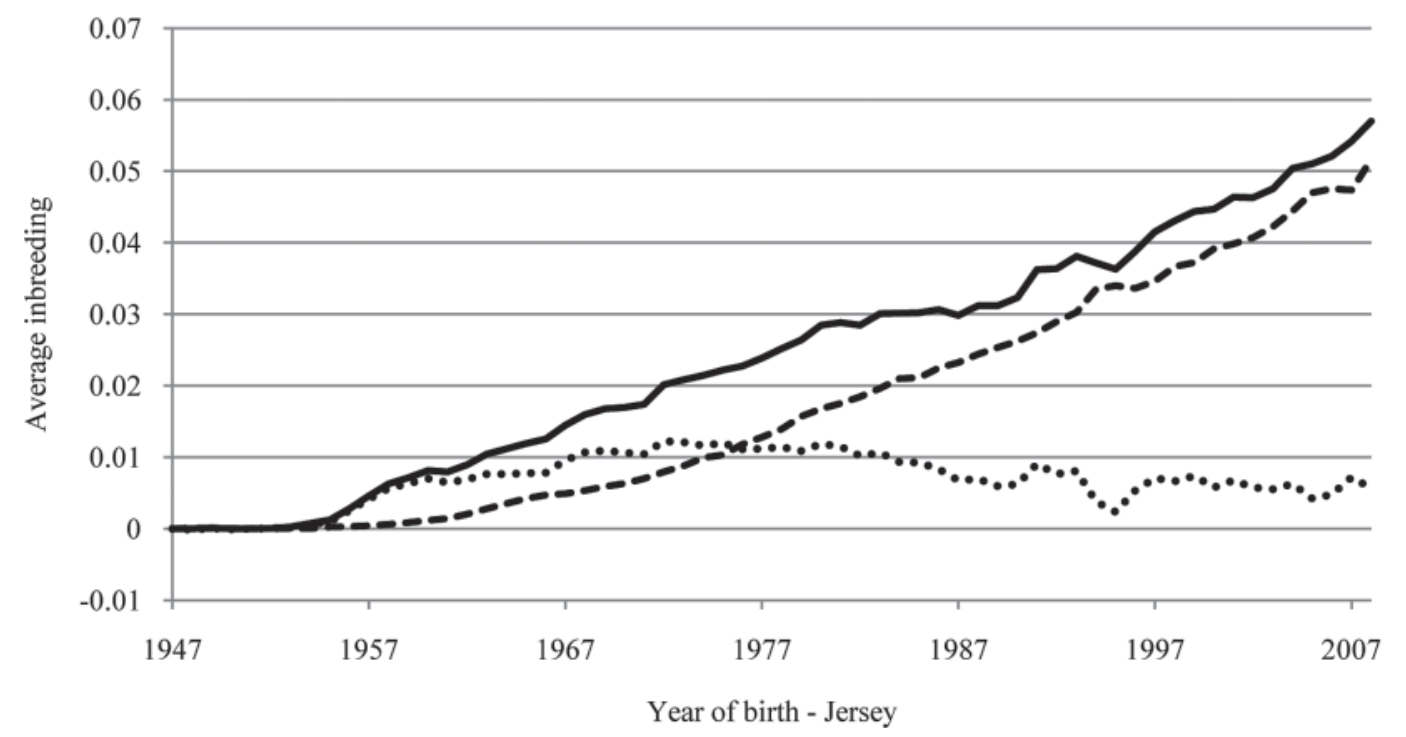

Figure 4. Average inbreeding coefficient for all animals $(\mathrm{F})$, average coancestry between sire and dam $\left(\mathrm{f}_{\mathrm{s}-\mathrm{d}}\right)$, and degree of nonrandom mating ( $\alpha$ ) (Holstein, 4a; Jersey, 4b).

coancestry for different time periods, are summarized in Table 2. In Holsteins, the generation intervals have consistently decreased since 1970, leading to faster turnover of generations. Nevertheless, the rates of inbreeding per generation varied over the time periods, being at the highest between 1990 and 1999, which led to an estimated $N_{e}$ of 33 . In recent years, however, the rate of inbreeding per generation was lowered, leading to a recent $N_{e}$ of 114. In Jerseys, as generation intervals decreased and rates of inbreeding and coancestry increased over time since $1980, N_{e}$ decreased to a current value of 54 .

\section{Genetic Contributions}

Table 3 shows the estimated values of the coefficients $f_{e}, f_{g e}, N_{e n f}$, and $N_{a}$, and numbers of ancestors that explain given percentages of the gene pool of cows born between 2000 and 2007 in Holsteins and between 2000 and 2006 in Jerseys, and of the gene pool of proven bulls born between 1998 and 2006 for both breeds. In Holsteins, all of the estimated coefficients were consistently higher for cows than for bulls. The effective number of ancestors in Holsteins was about 15 for cows and bulls, whereas $f_{e}$ was 19 -fold higher. The effective 
Table 2. Average generation interval (Gen. int.), average rate of inbreeding per generation $(\Delta \mathrm{F}, \%),{ }^{1}$ average rate of coancestry per generation $(\Delta \mathrm{C}, \%)$, effective population size $\left(N_{e}\right)$, and future $N_{e}$ predicted based on rates of coancestry

\begin{tabular}{|c|c|c|c|c|c|c|c|c|c|c|}
\hline Period & \multicolumn{5}{|c|}{ Holstein } & \multicolumn{5}{|c|}{ Jersey } \\
\hline $1980-1989$ & 6.37 & 0.52 & 0.87 & 97 & 57 & 6.54 & 0.33 & 0.60 & 153 & 84 \\
\hline 1990-1999 & 5.65 & 1.52 & 1.52 & 33 & 33 & 5.86 & 0.71 & 0.64 & 70 & 78 \\
\hline $2000-2007$ & 5.45 & 0.44 & 0.42 & 114 & 118 & 5.83 & 0.93 & 1.19 & 54 & 42 \\
\hline
\end{tabular}

${ }^{1}$ Inbreeding rates not accounting for missing pedigree records.

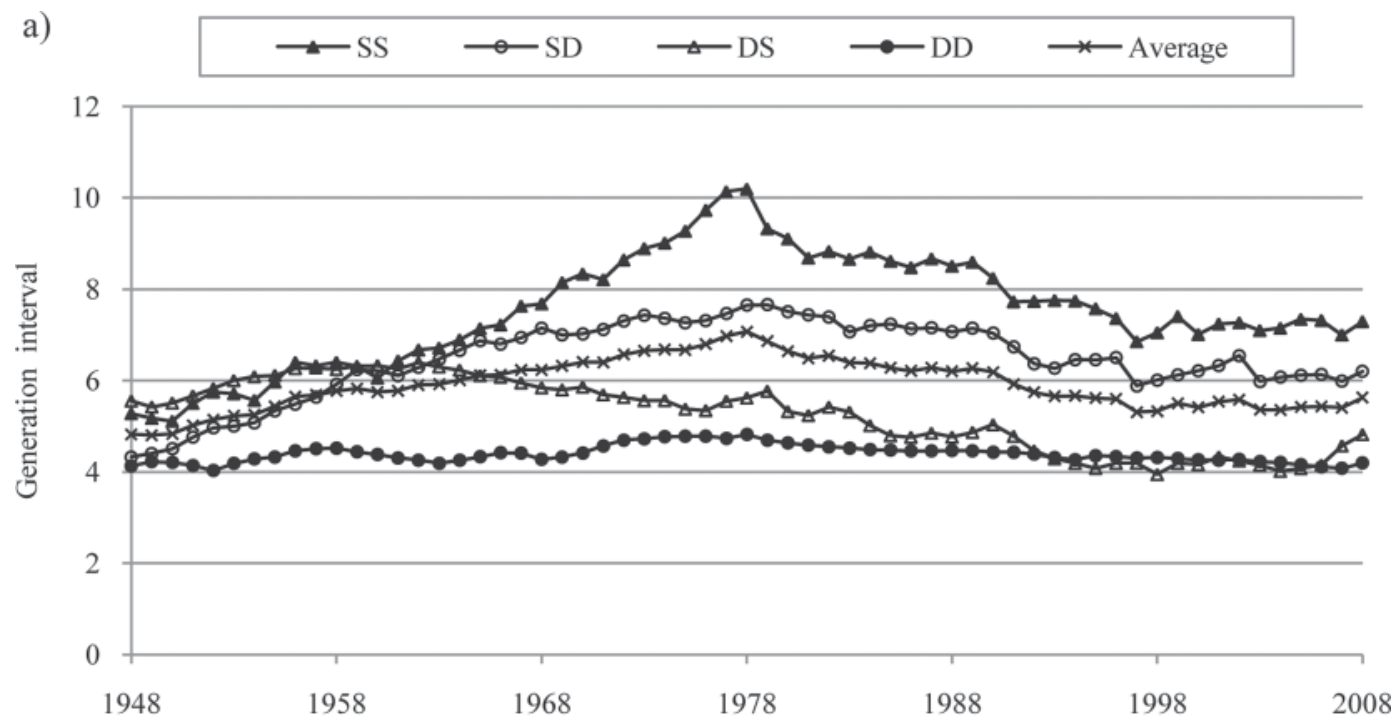

Year of birth - Holstein

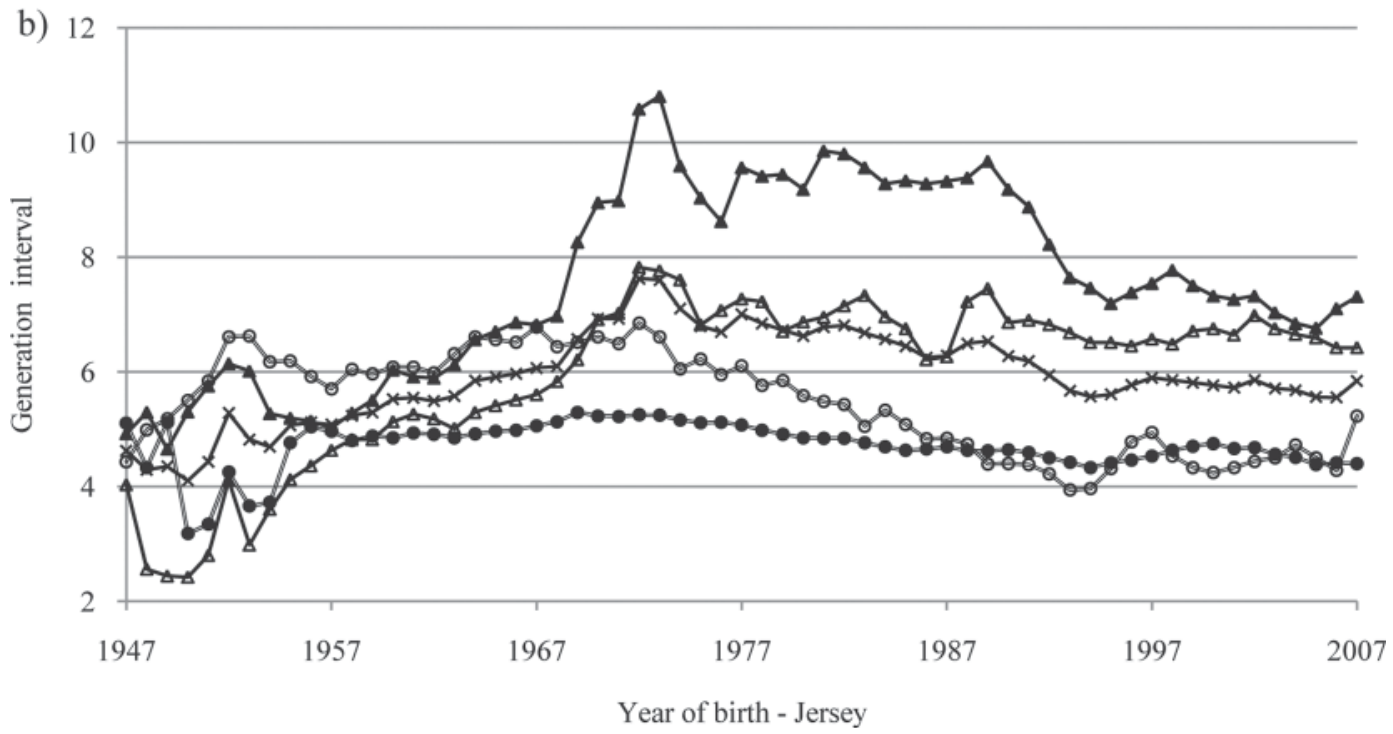

Figure 5. Generation intervals for 4 selection pathways [sire of sons (SS), sire of daughters (SD), dam of sons (DS), and dam of daughters (DD)] and average per birth year (Holstein, 5a; Jersey, 5b). 
Table 3. Effective number of founders $\left(\mathrm{f}_{\mathrm{e}}\right)$, effective number of founder genomes $\left(\mathrm{f}_{\mathrm{ge}}\right)$, effective number of nonfounders $\left(\mathrm{N}_{\mathrm{enf}}\right)$, effective number of ancestors $\left(N_{a}\right)$, and numbers of ancestors explaining a given percentage of the gene pool of cows born between 2000 and 2007 (Holsteins) and 2000 and 2006 (Jerseys) and proven bulls born between 1998 and 2006 in both breeds

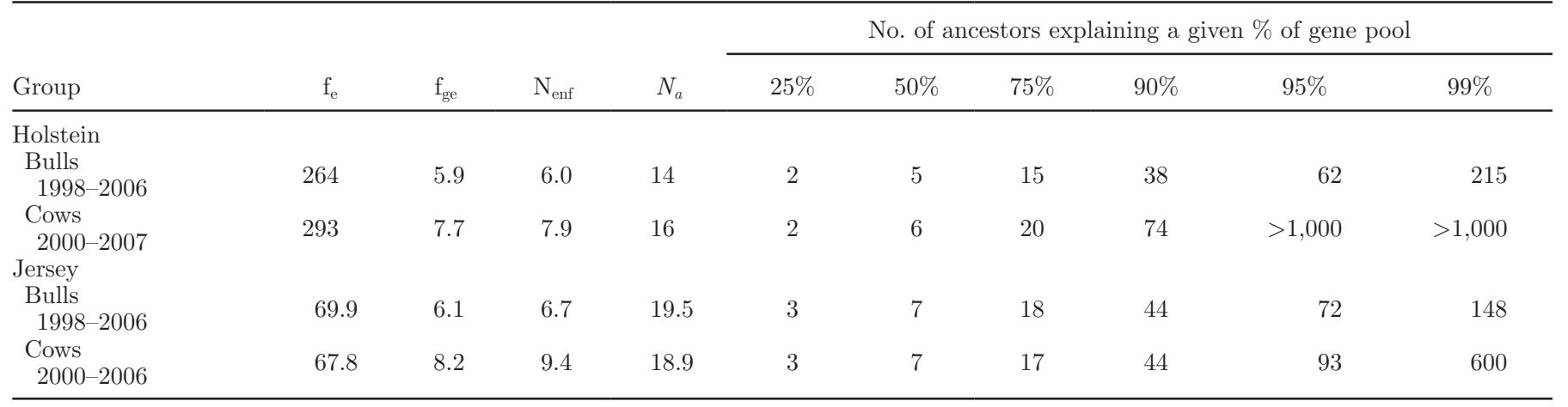

number of founder genomes was only 5.9 and 7.7 for bulls and cows, respectively. For all animals in the pedigree, $N_{a}, f_{e}$, and $f_{g e}$ reached values of 16,323 , and 7.7 in 2008, respectively (data not shown).

In Jerseys, $f_{e}$ and $N_{a}$ were slightly higher for bulls compared with cows, but $f_{g e}$ and $N_{\text {enf }}$ were slightly lower for bulls. In Jerseys, $N_{a}$ was about 19 for both bulls and cows, whereas $f_{e}$ was about 4 -fold higher. The effective number of founder genomes was only 6.1 and 8.2 for bulls and cows, respectively. For all animals in the pedigree, $N_{a}, f_{e}$, and $f_{g e}$ reached values of $18.6,75$, and 8.4 in 2007, respectively (data not shown).

The number of ancestors needed to explain a given percentage of the gene pool was consistently lower for bulls than for cows in Holsteins (Table 3). For instance, to explain $95 \%$ of the gene pool of bulls born between 1998 and 2006, 62 ancestors were needed, whereas to explain $95 \%$ of the gene pool of cows born between 2000 and 2007, more than 1,000 ancestors were needed. The corresponding features for Jerseys were 72 and 93 ancestors for bulls and cows, respectively.

\section{Genetic Diversity Loss}

The amount of genetic diversity lost in the 2 breeds since the late 1960s, due to different causes, is shown in Figure 6. In total, about $6.5 \%$ of genetic diversity in Holsteins was lost since the founder generations. From this loss, only about $2.3 \%$ could be attributed to unequal founder contributions. About $95 \%$ of the genetic diversity loss was due to genetic drift accumulated over nonfounder generations, caused mainly by the small effective population size, whereas only a minor contribution $(2.2 \%)$ could be attributed to possible bottlenecks, as depicted in Figure 6a.

Similarly in Jerseys, about $6 \%$ of genetic diversity was lost since the founder generations. About only $10 \%$ of the total loss could be attributed to unequal founder contributions. Most of the genetic diversity loss was due to genetic drift accumulated over nonfounder generations (80\%), caused by the small $N_{e}$, and some was attributed to bottlenecks (10\%), as depicted in Figure 6b.

\section{Ancestral Contributions}

Ten ancestors with the highest marginal genetic contribution to animals born between 2000 and 2008 for Holsteins and 2000 and 2007 for Jerseys are presented in Table 4. The average year of birth of those Holstein ancestors was 1969 and they accounted for $62 \%$ of the gene pool from 2000 to 2008. Two bulls alone, Round Oak Rag Apple Elevation and Pawnee Farm Arlinda Chief, contributed $30 \%$ of the gene pool. The average birth year of the 10 most-contributing Jersey ancestors was 1967, and they accounted for almost $60 \%$ of the gene pool from 2000 to 2007. Three bulls, Highland Magic Duncan, SS Quicksilver of Fallneva, and Marlu Milestone, contributed $29 \%$ of the gene pool.

As the marginal contributions of ancestor do not fully explain the genetic constitution of a population, the inbreeding of Holstein animals born between 2000 and 2008 and Jerseys born between 2000 and 2007 was decomposed into ancestral components to determine animals with highest contributions to inbreeding in recent years (Table 5). In Holsteins, the top 10 ancestors contributing to inbreeding accounted for $71 \%$ of total inbreeding of animals born in recent years. Round Oak Rag Apple Elevation contributed 19\% to the inbreeding, and his son, Hanoverhill Starbuck, another 11\%. In Jerseys, the top 10 ancestors with the largest contribution to inbreeding accounted for $60 \%$ of total inbreeding of animals born in recent years. Highland Magic Duncan alone contributed $14 \%$ to the inbreeding in recent years. 


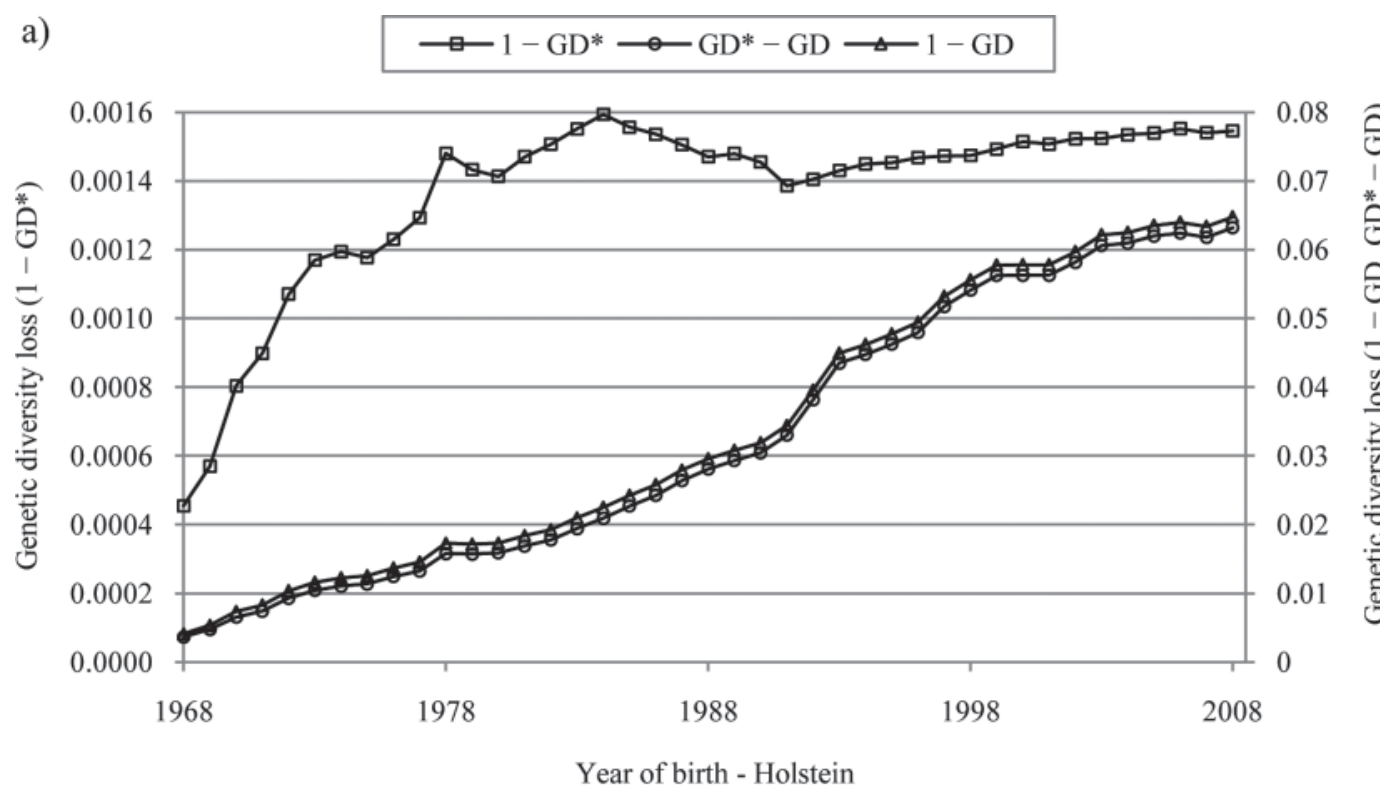

b)
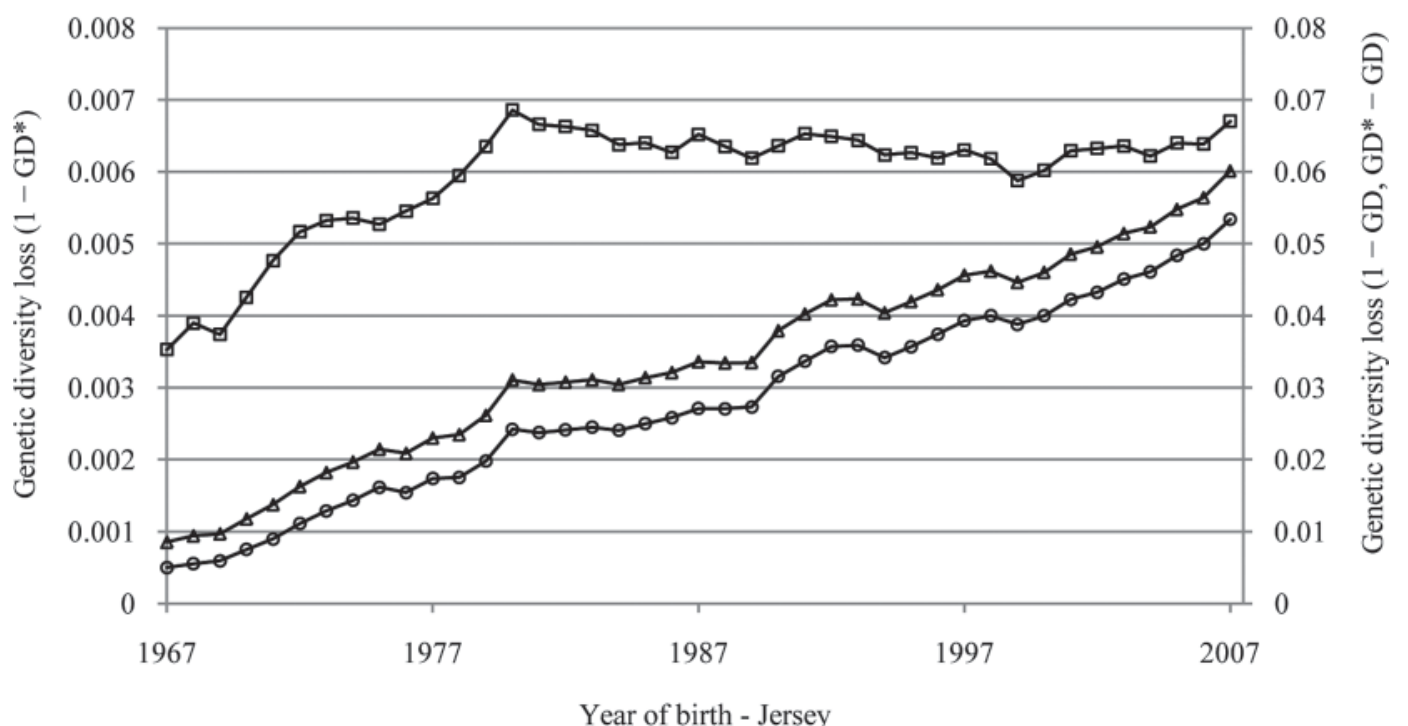

Figure 6. Genetic diversity (GD) loss due to unequal founder contributions (1-GD*, left axis), due to bottlenecks and genetic drift, and genetic drift only (1 - GD and GD* - GD, respectively, right axis) (Holstein, 6a; Jersey, 6b).

\section{DISCUSSION}

\section{Pedigree Completeness}

The overall completeness and depth of the pedigree was good in both breeds. In Holsteins, the completeness of the cows' pedigree seemed slightly better than of the overall population, with average 5-generation PCI values over $90 \%$ in the last $10 \mathrm{yr}$. The PCI of proven Holstein bulls was better than of cows, being $100 \%$, considering 5 generations back, and close to $90 \%$ for animals born after 2000 for 15 generations back. In Jerseys, the highest completeness was observed in cows. The 5 -generation PCI of proven bulls was above $90 \%$, whereas for cows it was above $95 \%$ in the last 20 yr. Sørensen et al. (2005) reported an average 5-generation PCI of 95 and $95 \%$ for Danish Holsteins and Danish Jerseys born between 1999 and 2003, respectively. In the current study, for the similar period, average 5-generation PCI for all animals in the pedigree was lower at 90 and $87 \%$ for Canadian Holsteins and Jerseys, respectively. 
Table 4. Summary statistics for 10 ancestors with the highest marginal genetic contributions to animals born between 2000 and 2008 (Holsteins), and 2000 and 2007 (Jerseys)

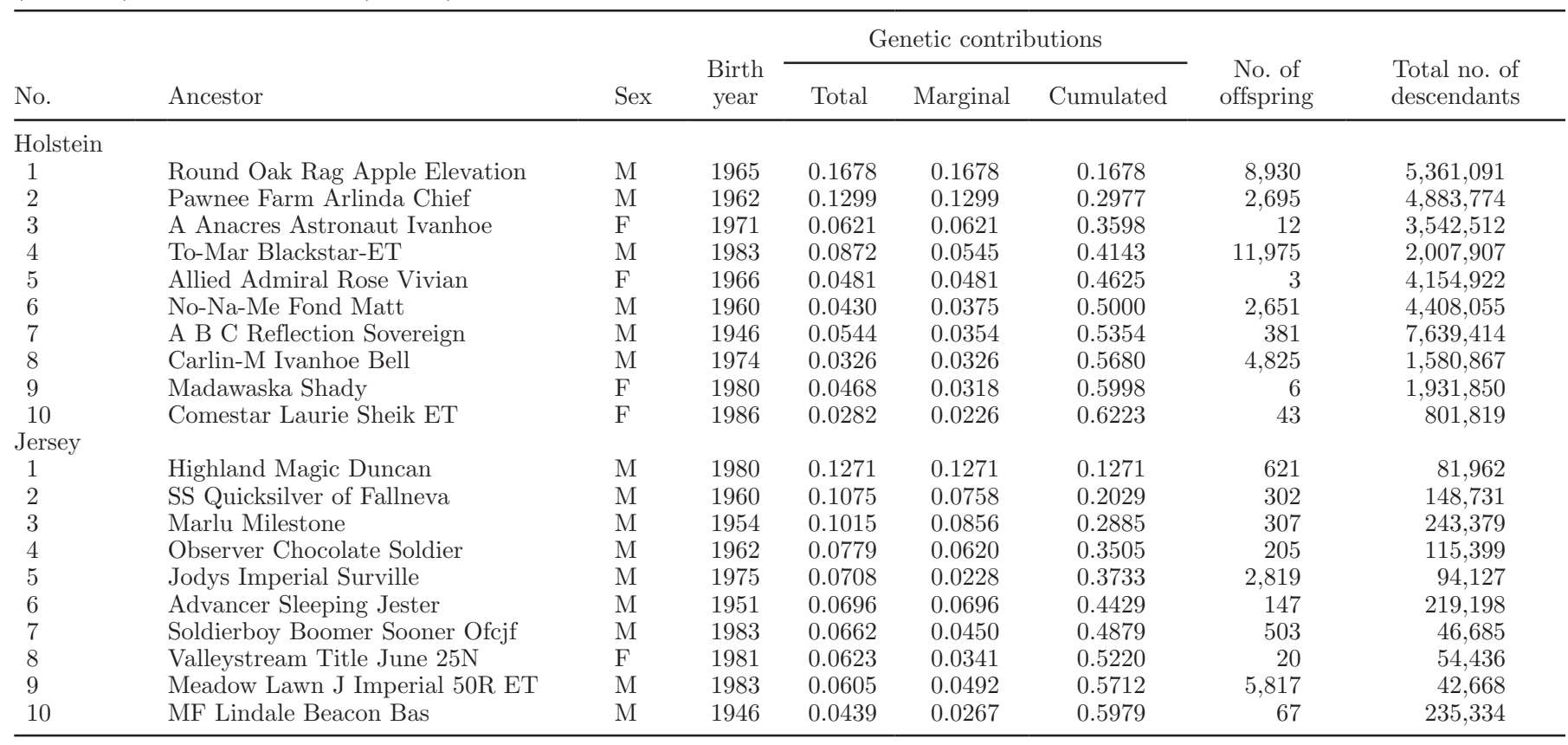

The average number of discrete generation equivalents reached about 15 and 10 in 2006 for Canadian Holsteins and Jerseys, respectively. These values are higher than those reported in Danish Holstein and Jersey in 1999 to 2003 (7.20 and 7.36, respectively) by Sørensen et al. (2005). Koenig and Simianer (2006) reported an average number of discrete generation equivalents of about 6 in Holstein cows born in the period of 1993 to 1999 in Germany. Hammami et al. (2007) reported average discrete generation equivalents of 8.2 and 6.3 in 2000 in Holstein cattle in Tunisia and Luxembourg, respectively.

Table 5. Summary statistics for 10 ancestors with the highest contributions to inbreeding of animals born between 2000 and 2008 (Holsteins), and 2000 and 2007 (Jerseys)

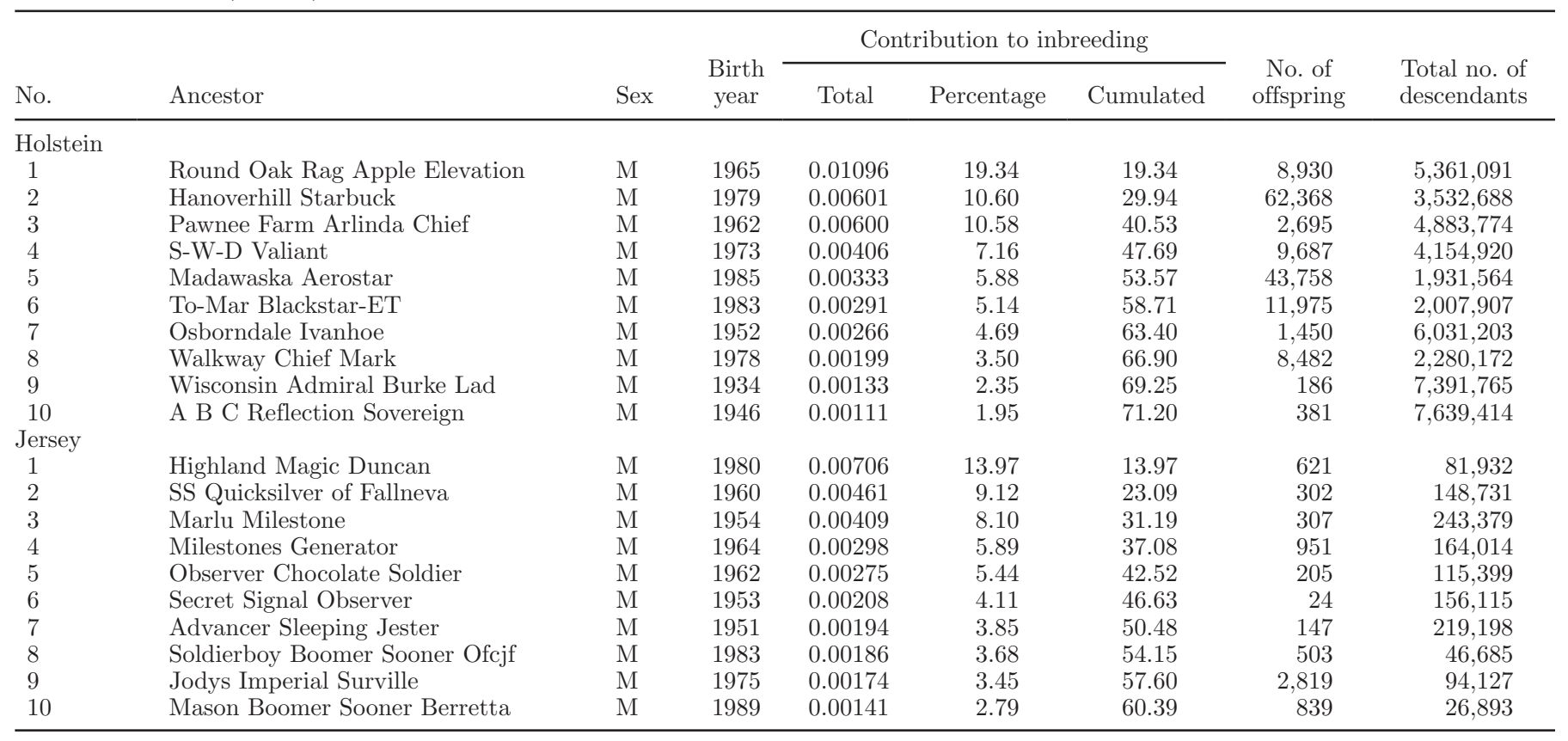




\section{Rates of Inbreeding and Coancestry}

The average rates of inbreeding per year and per generation in Holsteins were highest in the 1990s. The fast accumulation of inbreeding in the 1990s was likely associated with advancements in genetic evaluation methodology, such as the use of BLUP, strong selection pressure, and intensive use of AI. After 2000, the rates of inbreeding decreased, likely due to more awareness about the increase of inbreeding that happened in the 1990s and tools, such as the R-values introduced by Canadian Dairy Network, which possibly led to better selection and mating decisions in Holsteins aiming to minimize coancestry and inbreeding.

Muir (2011) analyzed insemination data provided to the Canadian Dairy Network by the major AI organizations in Canada and Canadian DHI partners since 2001. That study looked at the popularity of sires over time according to the number of inseminations and identified the 10 most popular sires in each year (all Holstein sires). In 2001, the 10 most popular sires accounted for $32.6 \%$ of all inseminations, whereas in 2005 , they accounted for $24.1 \%$ of inseminations. In 2010, the 10 most popular sires accounted for only $17.5 \%$ of all inseminations. As pointed out by Muir (2011), this indicates that Holstein breeders have been broadening their choices for sires outside the most popular ones in the last $10 \mathrm{yr}$.

For Jerseys, the rates of inbreeding per year and per generation increased since the 1980s, with no evidence of possible decrease in the near future, due to the increasing rates of coancestry and suboptimal mating decisions, as shown by the analysis of the degree of nonrandom mating.

For Holsteins, the amount of inbreeding that was recovered by accounting for missing pedigree records was relatively large despite the fact that very little of pedigree information was missing in recent years. However, this was not the case for animals born between 1900 and 1950 , where 50 to $70 \%$ of parentage information was missing. In addition, the average inbreeding coefficient of inbred animals was higher in those past years than for more recent animals, which helps to explain the 2-fold increase in average inbreeding coefficient when missing records were accounted for. However, the rates of inbreeding were very similar whether accounting or not for missing pedigree records. For Jerseys, the amount of inbreeding that was recovered by accounting for missing pedigree records was small and did not affect the estimated rates of inbreeding.

\section{Degree of Nonrandom Mating}

For Holsteins, the average inbreeding coefficient tended to be smaller than the average coancestry between sires and dams of animals born since the 1980s, especially after 2000. In contrast, for Jerseys, the average inbreeding coefficient was higher than the average coancestry between sires and dams since the 1950s. Consequently, the degree of nonrandom mating in Jerseys has been positive since the 1950s, whereas for Holsteins, it was positive up to the 1980s, but mostly negative after that. This implies that, in Holsteins, mating strategies have improved since the 1980s and mating of more highly than average-related individuals were successfully avoided. In Jerseys, individuals with higher than average coancestry were mated more often than would have been expected under random mating, which illustrates that mating decisions aiming to minimize inbreeding have not been effective in this breed. Minimum coancestry mating and R-values could be considered as tools to achieve this goal.

\section{Generation Interval and Effective Population Size}

The average generation interval in Holsteins and Jerseys has been decreasing since the 1970s. The main cause of this decrease was the decrease in the sire of son pathway from up to $10 \mathrm{yr}$ in the 1970s to about $7 \mathrm{yr}$ in recent years, which was due to the fact that, in the 1970s and 1980s, mainly second-crop bulls were used as sires of sons, whereas in the last study period, a higher number of newly proven sires have been used as sires of sons as soon as their first evaluation was published.

This decrease in average generation interval observed in the past is a favorable trend in terms of genetic progress, but not necessarily in terms of conservation of genetic diversity, because inbreeding and genetic drift may accumulate faster. With the application of genomic selection, generation intervals will further decrease, especially on the bull's side (Schaeffer, 2006), which will probably increase the annual rate of inbreeding.

According to Muir (2011), since 2009, most of the bulls in waiting for first proofs in Canada have genomically enhanced breeding values that are more reliable $(\sim 65 \%)$ than traditional parent averages for young and waiting bulls $(\sim 35 \%)$. Inseminations by this group of bulls totaled only about $11 \%$ in 2001 and 2005, but in 2010, more than $29 \%$ of inseminations were from sires with genomic parent averages waiting for their first official progeny proof. Consequently, the use of first-crop proven sires decreased from $49 \%$ in 2001 and 2005 to $32 \%$ in 2010 (Muir 2011). Therefore, the management of genetic diversity will become an even more important task in the near future. However, simulation studies showed that genomic selection may allow for new possibilities for the control of inbreeding and coancestry that should be exploited (Daetwyler et al., 2007; Stachowicz et al., 2008). 
Rates of inbreeding per generation reached the highest values between 1990 and 1999, which led to an estimated $N_{e}$ of 33 in Holsteins. For the similar time period, Sørensen et al. (2005) reported an $N_{e}$ of 49 in Danish Holsteins. In recent years, however, the rate of inbreeding per generation was lowered in Canadian Holsteins, leading to a recent $N_{e}$ of 114. In Canadian Jerseys, since the 1980s, the $N_{e}$ decreased to a current value of 54. Between 1990 and 1999, the estimated $N_{e}$ was 70, which was higher than that reported by Sørensen et al. (2005) for the similar time period in Danish Jerseys $\left(N_{e}=53\right)$. Genomic selection in Jerseys may further enhance the future decrease in $N_{e}$, as a consequence of decreased generation interval, which might have an additional negative effect on the increasing annual rates of inbreeding in this breed.

\section{Genetic Contributions}

In Holsteins, values for all estimated coefficients $\left(f_{e}\right.$, $f_{g e}, N_{e n f}$, and $N_{a}$ ) were higher for cows, which indicate that cows are more genetically diverse than bulls. This suggests that the selection process of bull dams might be optimized to produce bulls less related to the ones being currently used.

In general, using bulls less related to the Canadian population would be desirable in terms of conservation of population genetic diversity. However, as other studies have shown, finding such bulls may be difficult. The Holstein breed is a cosmopolitan population and, as suggested by Van Doormaal et al. (2005), a global effort would be needed to achieve this goal, given that in some countries groups of animals may exist that are less related to the ones globally used.

In Jerseys, $f_{e}$ and $N_{a}$ were slightly higher for bulls than cows, but $f_{g e}$ and $N_{e n f}$ were lower for bulls, which indicates that founder and ancestor representations might be more evenly distributed in bulls, but genetic drift seems to affect their genetic makeup more than cows in this breed.

The effective number of founders became fixed after a certain number of generations, as expected (Caballero and Toro, 2000). In Holsteins, for all animals, it reached a value of about 330 at the beginning of 1980s and was quite constant afterward (data not shown). The effective number of founder genomes has decreased over time, from around 10 in the 1990s to 7.7 for all animals born in 2008 (data not shown). When compared with the much higher effective number of founders, $f_{g e}$ indicates that, besides the unequal founder contributions, jointly bottlenecks and genetic drift were very important causes of the loss of genetic diversity in Holsteins. The $f_{g e}$ was, as expected, smaller than half the $N_{e}$, which indicates that random loss of founder alleles occurred as the result of genetic drift. The effective number of nonfounders was only slightly higher than $f_{g e}$ for all animals (data not shown), as it was also the case for bulls and cows (Table 3), which indicates that almost all of the genetic drift in the population occurred over nonfounder generations.

In Jerseys, founders contributions got fixed at the beginning of the 1980s and remained constant after that with a value of about 80 for all animals (data not shown). Similarly to Holsteins, $f_{g e}$ in the Jerseys has decreased over time and its value for animals born in recent years was below 10, reaching 8.3 in 2007 (data not shown). The same pattern was also observed for bulls and cows (Table 3). This shows that, besides the unequal founders contributions, jointly bottlenecks and genetic drift were also very important causes of diversity loss in Jerseys. As for Holsteins, $N_{\text {enf }}$ was only slightly higher than $f_{g e}$, which indicates that most of the genetic drift that occurred in the population accumulated over nonfounder generations.

\section{Loss of Genetic Diversity}

The main cause of loss of genetic diversity in Canadian Holsteins was shown to be genetic drift accumulated over nonfounder generations, which is mainly caused by the small $N_{e}$. Similarly in Jerseys, the main cause of loss of diversity was genetic drift accumulated over nonfounder generations; however, unequal contribution of founders and bottlenecks jointly contributed relatively more (20\%) to the total loss than in Holsteins $(5 \%)$.

Genetic drift was also identified as the main cause of genetic diversity loss in Canadienne, Milking Shorthorn, Brown Swiss, Guernsey, and Ayrshire breeds in Canada (Melka et al., 2008). Similarly, Honda et al. (2004) reported that, after 1980, the major reason for the decrease in genetic diversity in Japanese Black cattle was random genetic drift over the nonfounder generations.

\section{Ancestral Contributions}

In Holsteins, the 10 most-contributing ancestors accounted for $62 \%$ of gene pool in 2000 to 2008 . The large number of descendants from these bulls in the pedigree demonstrates how large the effect of these animals is on the genetic structure of the current Canadian Holstein population. Furthermore, those 10 ancestors were not always unrelated. Round Oak Rag Apple Elevation is grandfather of To-Mar Blackstar-ET on both sides of the pedigree; Madawaska Shady was also a descendant of Round Oak Rag Apple Elevation and dam of Madawaska Aerostar. 
Round Oak Rag Apple Elevation and A Anacres Astronaut Ivanhoe are parents of Hanoverhill Starbuck, one of the most famous and used Canadian bulls. Two other females among the 10 most-contributing ancestors are also dams of other important bulls.

An interesting observation is that 1 of the bulls in the list of the 10 most-contributing ancestors, Carlin-M Ivanhoe Bell, was the bull identified as the main carrier of complex vertebral malformation (CVM) genetic disorder (Agerholm et al., 2001).

The list of the most-contributing ancestors in Canadian Holsteins is very similar to lists in the United States (Young and Seykora, 1996), Denmark (Sørensen et al., 2005), Germany (Koenig and Simianer, 2006), and Luxemburg and Tunisia (Hammami et al., 2007). Round Oak Rag Apple Elevation, Hanoverhill Starbuck, Pawnee Farm Arlinda Chief, S-W-D Valiant, To-Mar Blackstar-ET, Osborndale Ivanhoe, Wisconsin Andmiral Burke Lad, A B C Reflection Sovereign, and Carlin-M Ivanhoe Bell appeared in the lists of most of these countries.

In Jerseys, the 10 most-contributing ancestors accounted for almost $60 \%$ of the gene pool in 2000 to 2007. They were also genetically related, with an average relationship of $17 \%$. The bull with the highest contribution, Highland Magic Duncan, which explained $13 \%$ of gene pool, was reported to contribute $4 \%$ of genes to the Danish Jersey population (Sørensen et al., 2005). He was also reported to be the bull with the highest relationship to the Jersey cow population in the United States (USDA-AIPL, 2009).

The decomposition of inbreeding of Holsteins born between 2000 and 2008 and Jerseys born between 2000 and 2007 into ancestral components showed that, in Holsteins, the top 10 ancestors accounted for $71 \%$ of the total inbreeding observed in the recent years. Round Oak Rag Apple Elevation contributed with $20 \%$ of the inbreeding, and his son Hanoverhill Starbuck another $10 \%$. The number of offspring of each of these bulls, their total number of descendants in the pedigree, and the fact that they are all very closely related to each other show how narrow the gene pool of Canadian Holsteins is, which is also depicted by the small effective number of founder genomes.

In Jerseys, the top 10 ancestors with the greatest contribution to inbreeding accounted for $60 \%$ of the total inbreeding in recent years. Highland Magic Duncan alone contributed $14 \%$ of the inbreeding in recent years. As for Holsteins, the number of offspring of each of the top 10 ancestors contributing to inbreeding, their total number of descendants in the pedigree, and the fact that they are related to each other show that the gene pool of Canadian Jerseys is also very narrow, which is, again, depicted by the small effective number of founder genomes.

\section{CONCLUSIONS}

The pedigree analyses of Canadian Holsteins and Jerseys indicated that both breeds have very limited gene pools and suffer from negative effects of accumulation of inbreeding and genetic diversity loss. The small effective population size is a consequence of long-term genetic selection pressure and AI, allowing for a very heavy use of top sires. Furthermore, the introduction of genomic selection may allow for significant decreases in generation intervals, which can cause faster accumulation of inbreeding over time and, consequently, faster loss of genetic diversity. Therefore, a need exists for managing selection and mating decisions to control future coancestry and inbreeding, which would lead to better handling of the $N_{e}$.

\section{ACKNOWLEDGMENTS}

The authors acknowledge the DairyGen Council of Canadian Dairy Network, and Natural Sciences and Engineering Research Council (NSERC) of Canada for funding this project and 2 anonymous reviewers for their suggestions and comments.

\section{REFERENCES}

Agerholm, J. S., C. Bendixen, O. Andersen, and J. Arnbjerg. 2001. Complex vertebral malformation in Holstein calves. J. Vet. Diagn. Invest. 13:283-289.

Berg, P., M. K. Sørensen, and J. Nielsen. 2007. EVA interface user manual. Accessed Dec. 10, 2008. http://eva.agrsci.dk/User\%20 Manual - updated_27-02-2009.pdf.

Bijma, P., and J. A. Woolliams. 1999. Prediction of genetic contributions and generation intervals in populations with overlapping generations under selection. Genetics 151:1197-1210.

Boichard, D. 2002. PEDIG: A Fortran package for pedigree analysis suited for large populations. Proc. 7th World Cong. Genet. Appl. Livest. Prod., Montpellier, France. CD-ROM communication no. $28-13$.

Boichard, D., L. Maignel, and E. Verrier. 1997. The value of using probabilities of gene origin to measure genetic variability in a population. Genet. Sel. Evol. 29:5-23.

Caballero, A., and M. A. Toro. 2000. Interrelations between effective population size and other tools for management of conserved populations. Genet. Res. 75:331-343.

Canadian Dairy Network. 2008. Inbreeding update. Accessed Jan. 30, 2011. http://www.cdn.ca/document.php?id=150.

Colleau, J. J. 2002. An indirect approach to the extensive calculation of relationship coefficients. Genet. Sel. Evol. 34:409-421.

Colleau, J. J., and M. Sargolzaei. 2008. A proximal decomposition of inbreeding, coancestry and contributions. Genet. Res. (Camb.) 90:191-198.

Daetwyler, H. D., B. Villanueva, P. Bijma, and J. A. Woolliams. 2007. Inbreeding in genome-wide selection. J. Anim. Breed. Genet. 124:369-376.

Falconer, D. S., and T. F. C. Mackay. 1996. Introduction to Quantitative Genetics. 4th ed. Longman Scientific and Technical, Harlow, UK. 
González-Recio, O., E. López de Maturana, and J. P. Gutiérrez. 2007. Inbreeding depression on female fertility and calving ease in Spanish dairy cattle. J. Dairy Sci. 90:5744-5752.

Hagger, C. 2005. Estimates of genetic diversity in the brown cattle population of Switzerland obtained from pedigree information. J. Anim. Breed. Genet. 122:405-413.

Hammami, H., C. Croquet, J. Stoll, B. Rekik, and N. Gengler. 2007. Genetic diversity and joint-pedigree analysis of two importing Holstein populations. J. Dairy Sci. 90:3530-3541.

Honda, T., T. Nomura, Y. Yamaguchi, and F. Mukai. 2004. Monitoring of genetic diversity in the Japanese Black cattle population by the use of pedigree information. J. Anim. Breed. Genet. 121:242-252.

Kearney, J. F., E. Wall, B. Villanueva, and M. P. Coffey. 2004. Inbreeding trend and application of optimized selection in UK Holstein population. J. Dairy Sci. 87:3503-3509.

Koenig, S., and H. Simianer. 2006. Approaches to the management of inbreeding and relationship in the German Holstein dairy cattle population. Livest. Sci. 103:40-53.

Lacy, R. C. 1989. Analysis of founder representation in pedigrees: Founder equivalents and founder genome equivalents. Zoo Biol. 8:111-123.

Lacy, R. C. 1995. Clarification of genetic terms and their use in the management of captive populations. Zoo Biol. 14:565-578.

MacCluer, J. W., A. J. Boyce, B. Dyke, L. R. Weitkamp, D. W. Pfennig, and C. J. Parsons. 1983. Inbreeding and pedigree structure in Standardbred horses. J. Hered. 74:394-399.

Melka, M. G., K. Stachowicz, M. Sargolzaei, F. Miglior, and F. S. Schenkel. 2008. Assessment of genetic diversity in Canadian colored dairy breeds using pedigree data. Proc. Canadian Soc. Anim. Sci. Annu. Mtg., Guelph, Ontario, Canada. CD-ROM communication no. PC13.

Miglior, F. 2000. Impact of inbreeding-Managing a declining Holstein gene pool. Pages 108-113 in Proc. 10th World Holstein Friesian Fed. Conf., Sydney, NSW, Australia.

Miglior, F., and E. B. Burnside. 1995. Inbreeding of Canadian Holstein cattle. J. Dairy Sci. 78:1163-1167.

Miglior, F., B. J. Van Doormaal, and G. Kistemaker. 2008. Phenotypic analysis of inbreeding depression for traits measured in Canadian dairy cattle breeds. Accessed Jan. 30, 2011. http://www.cdn.ca/ Articles/GEBMAY2008/Industry_Session_Agenda-May2008.pdf.

Muir, B. 2011. Trends in sire usage. Accessed Jan. 30, 2011. http:// www.cdn.ca/document.php?id=217.
Sargolzaei, M., H. Iwaisaki, and J. J. Colleau. 2005. A fast algorithm for computing inbreeding coefficients in large populations. J. Anim. Breed. Genet. 122:325-331.

Sargolzaei, M., H. Iwaisaki, and J. J. Colleau. 2006. CFC: A tool for monitoring genetic diversity. Proc. 8th World Congr. Genet. Appl. Livest. Prod., Belo Horizonte, Brazil. CD-ROM Communication $27-28$.

Schaeffer, L. R. 2006. Strategy for applying genome-wide selection in dairy cattle. J. Anim. Breed. Genet. 123:218-223.

Sölkner, J., L. Filipcic, and N. Hampshire. 1998. Genetic variability of populations and similarity of subpopulations in Austrian cattle breeds determined by analysis of pedigrees. Anim. Sci. 67:249256.

Sørensen, A. C., M. K. Sørensen, and P. Berg. 2005. Inbreeding in Danish dairy cattle breeds. J. Dairy Sci. 88:1865-1872.

Stachowicz, K., M. Sargolzaei, J. W. Wilton, and F. S. Schenkel. 2008. Inbreeding and selection response for genome-wide selection vs. traditional selection. Proc. Canadian Society of Animal Science Annu. Mtg., Guelph, Ontario, Canada. CD-ROM communication no. BGP5.

USDA-AIPL (Animal Improvement Programs Laboratory). 2009. Bovine inbreeding trends. Accessed Nov. 04, 2009. http://aipl.arsusda.gov/eval/summary/inbrd.cfm.

Van Doormaal, B. J., G. Kistemaker, and P. Brand. 2003. Development of "R-Values" to represent an animal's genetic relationship to the active female population. Accessed Nov. 30, 2009. http://cgil. uoguelph.ca/dcbgc/Agenda0309/agenda0309.htm.

Van Doormaal, B. J., F. Miglior, G. Kistemaker, and P. Brand. 2005. Genetic diversification of the Holstein breed in Canada and internationally. Interbull Bull. 33:93-97.

VanRaden, P. M. 1992. Accounting for inbreeding and crossbreeding in genetic evaluation of large population. J. Dairy Sci. 75:3136-3144.

Wright, S. 1931. Evolution in Mendelian populations. Genetics 16:97159

Wright, S. 1969. Evolution and the Genetics of Populations, Vol. 2: Theory of Gene Frequencies. University of Chicago Press, Chicago, IL.

Young, C. W., and A. J. Seykora. 1996. Estimates of inbreeding and relationship among registered Holstein females in the United States. J. Dairy Sci. 79:502-505. 